\title{
Alteration in Activation Pattern of Neck Muscles in Patients with Chronic Neck Pain
}

\author{
${ }^{1}$ Rajwant Kaur Chahal, ${ }^{2}$ Pravin Kumar
}

\begin{abstract}
Objective: The aim of this study was to investigate activation pattern of neck muscles in patients with chronic neck pain of nontraumatic origin during static tasks.
\end{abstract}

Materials and methods: Fifteen normal subjects were taken in group $A$ and 15 patients with chronic neck pain of nontraumatic origin were taken in group B. Electromyography (EMG) activity was recorded from the sternocleidomastoid, anterior scalene, levator scapulae and upper trapezius muscles. Percentage maximum voluntary isometric contraction were calculated during static tasks, which included shoulder abduction to $90^{\circ}$ and hold, shrug and hold, craniocervical flexion and hold.

Results: There was no significant $(p>0.05)$ difference found in activation pattern of neck muscles when we compared right and left sides within groups $A$ and $B$. But when we compared between groups, group B showed a significant $(p<0.05)$ increased activation pattern in anterior scalene, sternocleidomastoid, upper trapezius compared to normal subject's neck muscles except levator scapulae which shows no significant difference between groups.

Conclusion: It is concluded from the study that, in patient of nontraumatic origin of chronic neck pain, all the patients showed a significant increased level of EMG activity in neck muscles during performance of static activities as compared to asymptomatic controls.

Keywords: EMG, Cervical muscles, Cervical radiculopathy, Movement dysfunction.

How to cite this article: Chahal RK, Kumar P. Alteration in Activation Pattern of Neck Muscles in Patients with Chronic Neck Pain. Int J Head Neck Surg 2015;6(1):1-7.

Source of support: Nil

Conflict of interest: None

\section{INTRODUCTION}

Neck pain with a proposed cervical etiology or contribution is highly prevalent disorder. Motor aspects of muscle trigger points may include disturbed motor function, muscle weakness and most importantly muscle stiffness. ${ }^{1}$

The patients with chronic pain frequently exhibit rigid and guarded movement patterns and postural

\footnotetext{
${ }^{1}$ Student, ${ }^{2}$ Associate Professor

1,2Department of Physiotherapy, DAV Institute of Physiotherapy and Rehabilitation, Jalandhar, Punjab, India

Corresponding Author: Pravin Kumar, Associate Professor Department of Physiotherapy, DAV Institute of Physiotherapy and Rehabilitation, Jalandhar, Punjab, India, Phone: 9815365870, e-mail: pravin_pt@rediffmail.com
}

asymmetries. ${ }^{2}$ It is suggested that this habituated adaptation of movement and postures affects the motor strategies including the activation patterns of muscles. ${ }^{3}$

Various studies performed on patients with chronic neck pain of traumatic origin have reported increased activity in the superficial cervical muscles. ${ }^{4}$

Further adding to these findings increased activity in the upper trapezius during the performance of a functional task in patients with neck pain was demonstrated. ${ }^{5,6}$

Thus, this study aimed to investigate neck muscle activation patterns during static tasks between patients with chronic neck pain of nontraumatic origin and normal subjects.

\section{MATERIALS AND METHODS}

Study design was observational in nature. Total duration of study was one and half year. A total of 30 subjects were taken in the study. All the subjects were selected according to the criteria:

\section{Inclusion Criteria}

- Age: 20 to 45 years

- Gender-both males and females

- Duration of neck pain of at least 6 months

- Patient cooperative and mentally fit

- Normal individuals between the age of 20 and 45 years.

\section{Exclusion Criteria}

- Fracture of upper limb

- Patients with neurological or psychological problems

- Intra or extraspinal tumors

- Referred cardiac pain

- Rotator cuff injury

- Thoracic outlet syndrome.

\section{ELECTRODE PLACEMENT}

Single pair of electrodes was applied following careful skin preparation. It was cleaned with $70 \%$ alcohol to reduce skin impedance. The electrodes were cited, after careful palpation parallel to the underlying muscle fibers with a $20 \mathrm{~mm}$ inter electrode distance. For sternocleidomastoid (SCM), electrodes were placed at 
the point of intersection of the lines joining the sternal notch to mastoid process and another perpendicular to it in direction of muscle fibers. Electrodes for anterior scalene (AS) were placed along the line running parallel to the lateral border of clavicular portion of SCM. ${ }^{7}$ Electrodes for levator scapulae (LS) were centered laterally to C3-4 spinous process between the posterior margin of SCM and anterior margins of upper trapezius (UT). For UT electrodes were located $1 \mathrm{~cm}$ lateral to midpoint of a line connecting the acromion and C7 spinous process and second electrode was attached $2 \mathrm{~cm}$ laterally on same line. ${ }^{8}$ Ground electrode was placed at the ventral aspect of forearm. ${ }^{9}$

\section{PROCEDURE}

\section{Procedure for Data Collection}

A written consent was obtained, and the required assessment and evaluation was done. The maximal voluntary isometric contraction in manual muscle test position specific to each muscle or muscle part of interest was recorded. ${ }^{10}$ This was used for normalization of electromyography (EMG) recordings during each activity.

\section{MVIC for UT}

Subject was in sitting position and performed static contraction of shoulder abduction with the arm at $90^{\circ}$ abduction and neutral shoulder rotation. Resistance was provided proximal to the elbow joint (Fig. 1). The best/ maximum 1 second activity of 3 trials of 10 seconds each with the 30 seconds rest period between trials was taken as maximum voluntary isometric contraction (MVIC). ${ }^{11}$

\section{MVIC for AS}

Subject was in supine lying position and asked to perform static neck flexion against the manual resistance applied over the forehead (Fig. 2). Three trials of 10 seconds each with 30 seconds rest period between trials were conducted. The best/maximum 1 second activity was taken as MVIC.

\section{MVIC for LS}

Subject was in sitting position with his neck laterally rotated to same side and asked to perform a static shoulder elevation against the manual resistance applied over the shoulder (Fig. 3). The best/maximum 1 second activity of 3 trials of 10 seconds each with the 30 seconds rest period between trials was taken as MVIC.

\section{MVIC for SCM}

Subject in supine lying and asked to performed static neck flexion with the neck laterally flexed to the same side and rotated to the opposite side. Manual, maximal resistance was applied over forehead with a magnitude equal to subjects' efforts such that the contraction to be isometric (Fig. 4). The contraction was held for 10 seconds. After a rest period of 30 seconds, this was repeated for 3 trials. The best/maximum 1 second activity was taken as MVIC.

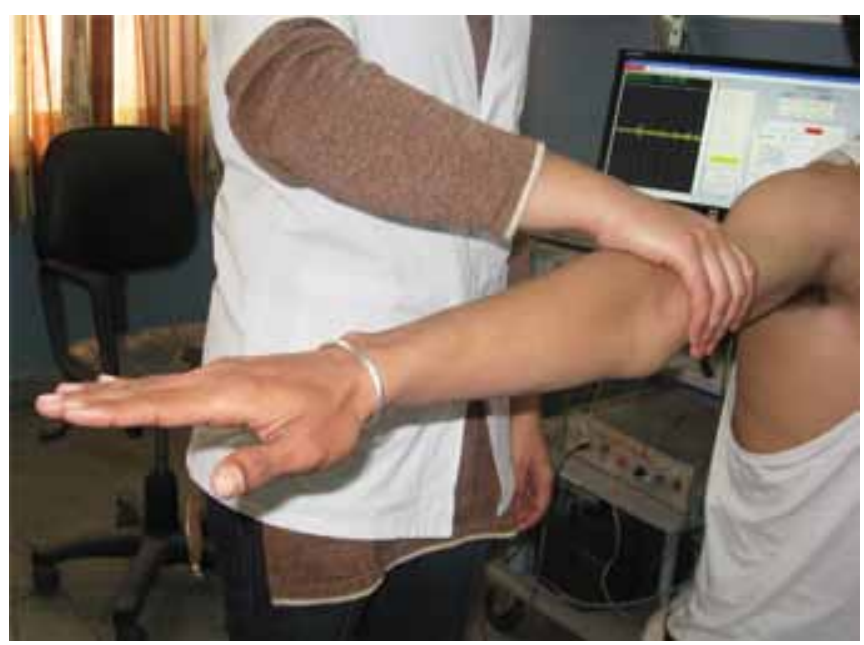

Fig. 1: MVIC upper trapezius

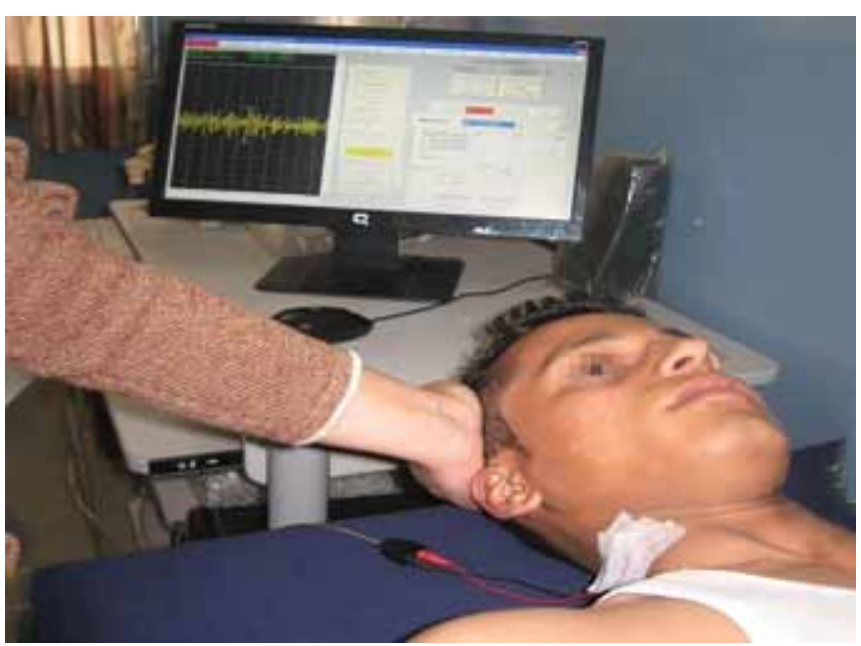

Fig. 2: MVIC anterior scalene

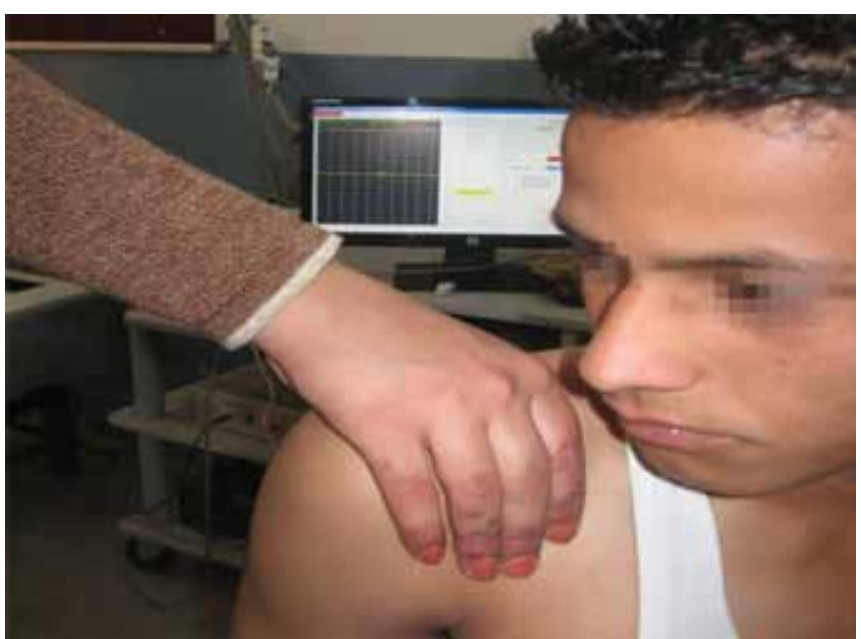

Fig. 3: MVIC levator scapulae 


\section{STATIC TASKS}

\section{Abduction}

Subject was in sitting position on a stool with hip, knee and ankle at $90^{\circ}$ trunk straight and the face looking straight forward. Arms were positioned at the side of the body. Subjects were instructed to take arm till $90^{\circ}$ abduction (Fig. 5).

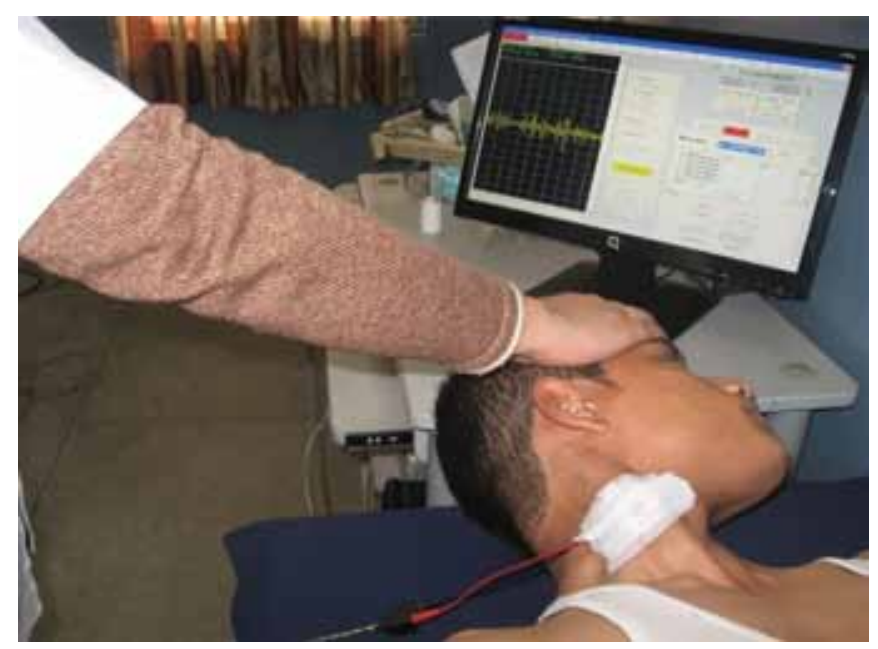

Fig. 4: MVIC sternocleidomastoid

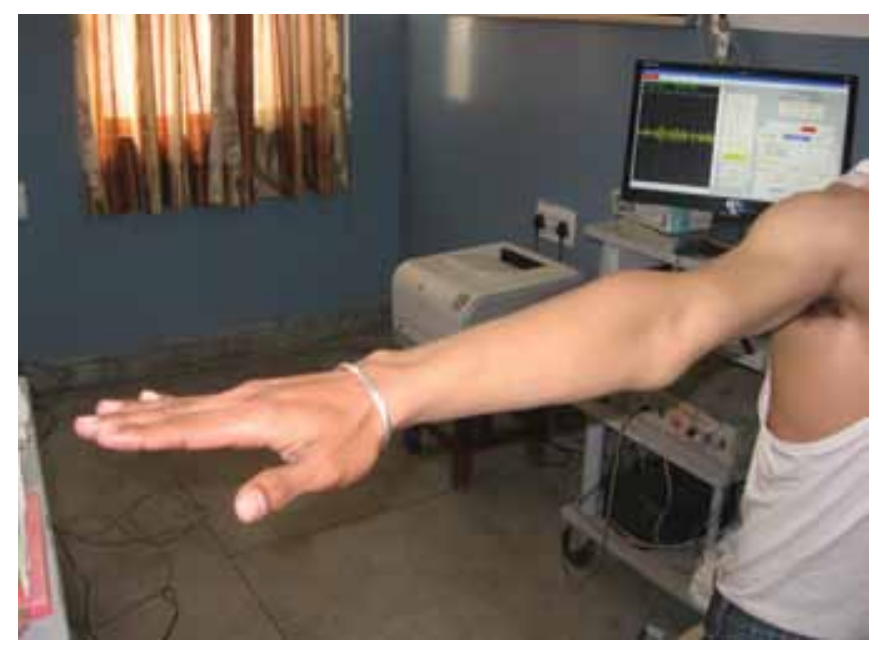

Fig. 5: Abduction

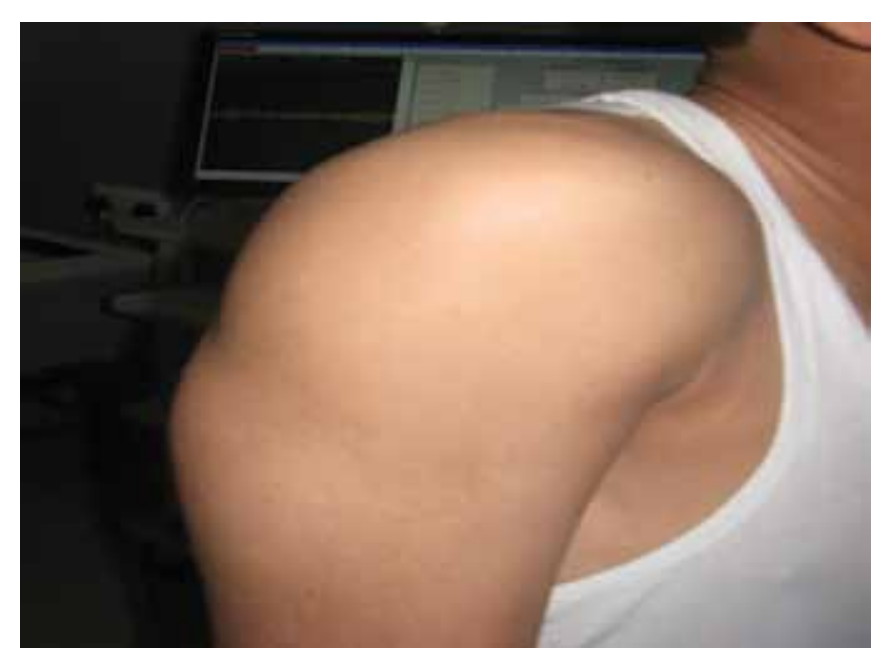

Fig. 6: Shrug

\section{Shrug}

Subject in the same position and instructed to perform a shrug up to ear level and sustain it in this position for 5 seconds duration and the muscle activation pattern observed (Fig. 6).

\section{Craniocervical Flexion}

Subject in supine lying position sagitally symmetrical and instructed to perform craniocervical flexion but with shoulders on the plinth and sustain it in this position for 5 seconds duration and muscle activation observed (Fig. 7).

\section{Data Analysis}

Statistics was performed by using the SPSS 13.0 software. The Chi-square test was used at the start of study to compare gender between the groups. Unpaired t-test was used for age and statistical analysis and differences in activation pattern between groups. Paired t-test was used to analyze the difference in activation pattern between the right and left sides. The significant level selected for this study was $\mathrm{p}<0.05$.

\section{RESULTS}

This study included two groups. Group A was consisting of 15 normal subjects with 5 males and 10 females with mean age of $22.46( \pm 2.29)$, and group B consisting of 15 chronic neck pain patients with 3 males and 12 females with mean age of $22.87( \pm 1.99)$. There was no statistically significant difference between both the groups in terms of age and gender (Table 1).

\section{Comparison within Group A}

In group A during the performance of shrug and craniocervical flexion, there was no significant difference ( $p>0.05$ ) found in activation pattern of upper trapezius,

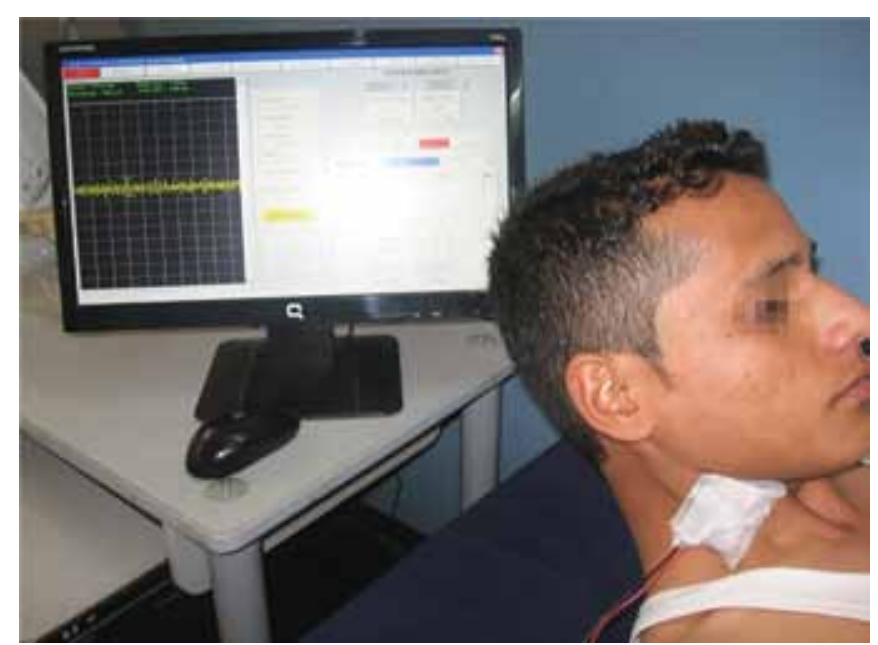

Fig. 7: Craniocervical flexion 
LS, SCM and AS except in UT which showed a significant difference $(p<0.05)$ in activation pattern between right and left side during abduction (Table 2 and Graph 1).

\section{Comparison within Group B}

In group B during the performance of abduction, shrug and craniocervical flexion, there was no significant difference $(p>0.05)$ in activation pattern of all neck muscles between right and left sides (Table 3 and Graph 2).

\section{Comparison between Groups A and B of Right Side Activity}

When we compared right side neck muscle between groups A and B during performance of abduction, shrug and craniocervical flexion, group B showed significant

Table 1: Basic characteristics of the subjects

\begin{tabular}{lll}
\hline & Group $A$ & Group B \\
\hline Total no. & 15 & 15 \\
Male/female & $5 / 10$ & $3 / 12$ \\
Mean age & $22.47 \pm 2.29$ & $22.87 \pm 1.99$ \\
\hline
\end{tabular}

increase $(\mathrm{p}<0.05)$ in activation pattern of neck muscles except in LS which showed nonsignificant difference ( $p>0.05)$ during shrugging activity (Table 4 and Graph 3).

\section{Comparison between Groups A and B of Left Side Activity}

When we compared left side neck muscle activity between groups A and B, there was no significant difference ( $p>0.05)$ found in activation pattern of LS and UT during abduction and shrugging but, during craniocervical flexion, it showed a significant increase $(\mathrm{p}<0.05)$ in activation pattern of SCM and AS in groups B (Table 5 and Graph 4).

\section{DISCUSSION}

The result of this study showed that there is altered pattern of muscle activation identified for the patients with chronic neck pain of nontraumatic origin during the performance of various tasks confirm the results of previous research, which demonstrated aberrant patterns of neck muscle activation in patients with neck pain.

Table 2: Comparison within group $A$

\begin{tabular}{llllll}
\hline Activity & Muscle & Right side $($ mean $\pm S D)$ & Left side $($ mean \pm SD) & $t$-value & Significance \\
\hline Abduction & UT & $21.20 \pm 6.84$ & $28.21 \pm 11.81$ & 3.537 & $*$ \\
Shrug & UT & $26.25 \pm 12.61$ & $31.46 \pm 13.28$ & 1.311 & $\mathrm{NS}$ \\
& LS & $51.70 \pm 19.49$ & $51.04 \pm 23.30$ & -0.164 & $\mathrm{NS}$ \\
Craniocervical flexion & SCM & $33.38 \pm 14.38$ & $35.99 \pm 12.13$ & 1.07 & $\mathrm{NS}$ \\
& AS & $49.64 \pm 17.50$ & $46.71 \pm 20.64$ & -0.77 & $\mathrm{NS}$ \\
\hline
\end{tabular}

${ }^{*}$ Significant $(p<0.05)$; NS: Nonsignificant $(p>0.05)$

Table 3: Comparison within group B

\begin{tabular}{llllll}
\hline Activity & Muscle group & Right side (mean \pm SD) & Left side $($ mean \pm SD) & $t$-value & Significance \\
\hline Abduction & UT & $31.72 \pm 12.25$ & $34.85 \pm 11.46$ & 0.71 & NS \\
Shrug & UT & $42.97 \pm 22.76$ & $40.9 \pm 25.18$ & -0.22 & NS \\
Craniocervical flexion & SS & $57.26 \pm 11.37$ & $65.9 \pm 16.28$ & 1.53 & NS \\
& SCM & $51.32 \pm 19.96$ & $47.62 \pm 17.88$ & -0.60 & NS \\
& AS & $72.52 \pm 22.29$ & $72 \pm 25.08$ & -0.66 & NS \\
\hline
\end{tabular}

NS: Nonsignificant $(p>0.05)$

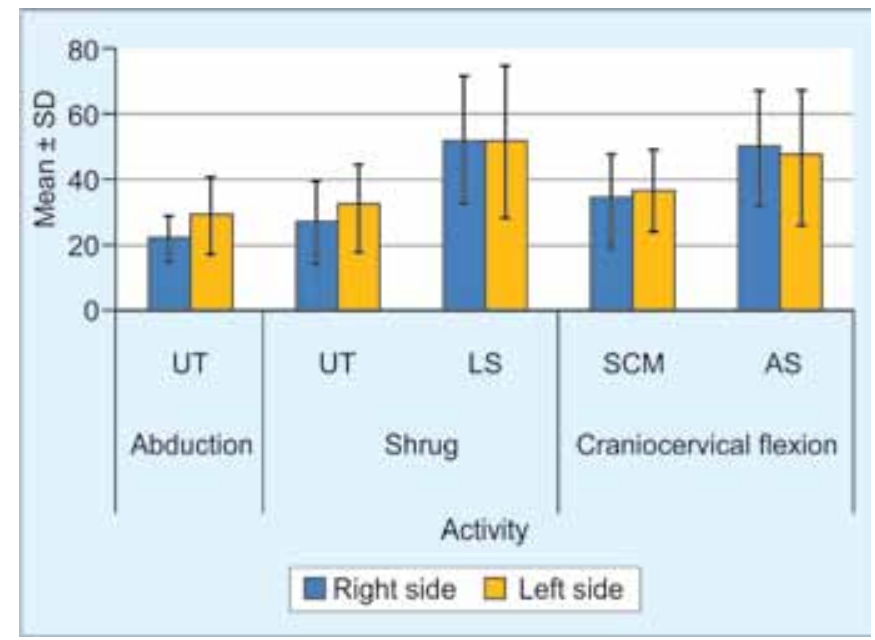

Graph 1: Comparison within group A

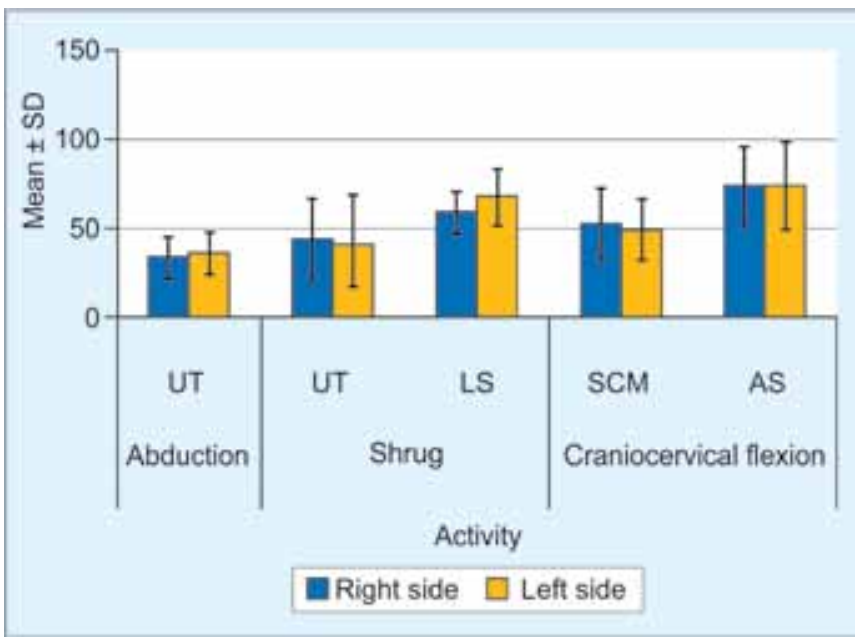

Graph 2: Comparison within group B 
There is significant increase in EMG activity demonstrated in different neck muscles in subjects with chronic neck pain when compared to normal subjects. Various mechanisms have been proposed by researchers to explain the increased EMG activity obtained in most of these studies. Elert J et al suggested that pain was a consequence of sustained spasm and that chronic pain disorders were characterized by a vicious cycle of pain and hyperactivity. They termed this as the hyperactivity model. ${ }^{12,13}$

Schmidt et al proposed that this was mediated by the muscle spindle system. During muscle contraction metabolites and low $\mathrm{pH}$ are produced which activates the nociceptive fibers, in turn activating motor neurons. Elevated motor neuron activity produce elevated muscle spindle activity and/or sensitivity, in turn increasing muscle fiber activity. ${ }^{14}$

According to Johansson and Sojka, metabolites produced by (static) muscle contractions stimulate groups III and IV muscle afferents, which activate gamma-motor neurons projecting to both homonymous and hetero- nymous muscles. The gamma-motor neurons influence the stretch sensitivity and discharges of secondary and primary spindle afferents. Increased activity in the primary muscle spindle afferents enhances the muscle stiffness, which leads to further production of metabolites in both homo and heteronymous muscles. Increased activity is secondary spindle afferents, which project back to the gamma system, constitutes a 'built in' second positive feedback loop which may perpetuate the condition with less 'support' from activity in groups III and IV muscle afferents. ${ }^{15}$

The patients with chronic pain frequently exhibit rigid and guarded movement patterns and postural asymmetries. ${ }^{2}$ Kasman GS et al suggested this habituated adaptation of movement and postures affects the motor strategies including the activation patterns of muscles. ${ }^{3}$

Psychological or occupational neck stress, precipitate the muscle spasm or even abnormal posture. It is well known that mental state affects the posture, which may lead to, altered activation pattern. The hyperactivity

Table 4: Comparison between groups $A$ and $B$ of right side activity

\begin{tabular}{lllllll}
\hline Activity & Muscle group & Side & Group A & Group B & $t$-value & Significance \\
\hline Abduction & UT & Right & $21.20 \pm 6.84$ & $31.72 \pm 12.25$ & 3.18 & $*$ \\
Shrug & UT & Right & $26.25 \pm 12.61$ & $42.97 \pm 22.76$ & 2.64 & $*$ \\
& LS & Right & $51.70 \pm 19.49$ & $57.26 \pm 11.37$ & 1.18 & NS \\
Craniocervical flexion & SCM & Right & $33.38 \pm 14.38$ & $51.32 \pm 19.96$ & 2.96 & $*$ \\
& AS & Right & $49.64 \pm 17.50$ & $72.52 \pm 22.29$ & 3.54 & $*$ \\
\hline
\end{tabular}

*Significant $(p<0.05)$; NS: Nonsignificant $(p>0.05)$

Table 5: Comparison between groups $A$ and $B$ of left side activity

\begin{tabular}{lllllll}
\hline Activity & Muscle group & Side & Group A (mean \pm SD) & Group B (mean \pm SD) & $t$-value & Significance \\
\hline Abduction & UT & Left & $28.21 \pm 11.81$ & $34.85 \pm 11.46$ & 1.56 & NS \\
Shrug & UT & Left & $31.46 \pm 13.28$ & $40.9 \pm 25.18$ & 1.28 & NS \\
& LS & Left & $51.04 \pm 23.30$ & $65.9 \pm 16.28$ & 2.02 & NS \\
Craniocervical flexion & SCM & Left & $35.99 \pm 12.13$ & $47.62 \pm 17.88$ & 2.08 & $*$ \\
& AS & Left & $46.71 \pm 20.64$ & $72 \pm 25.08$ & 3.01 & $*$ \\
\hline
\end{tabular}

*Significant $(p<0.05)$; NS: Nonsignificant $(p>0.05)$

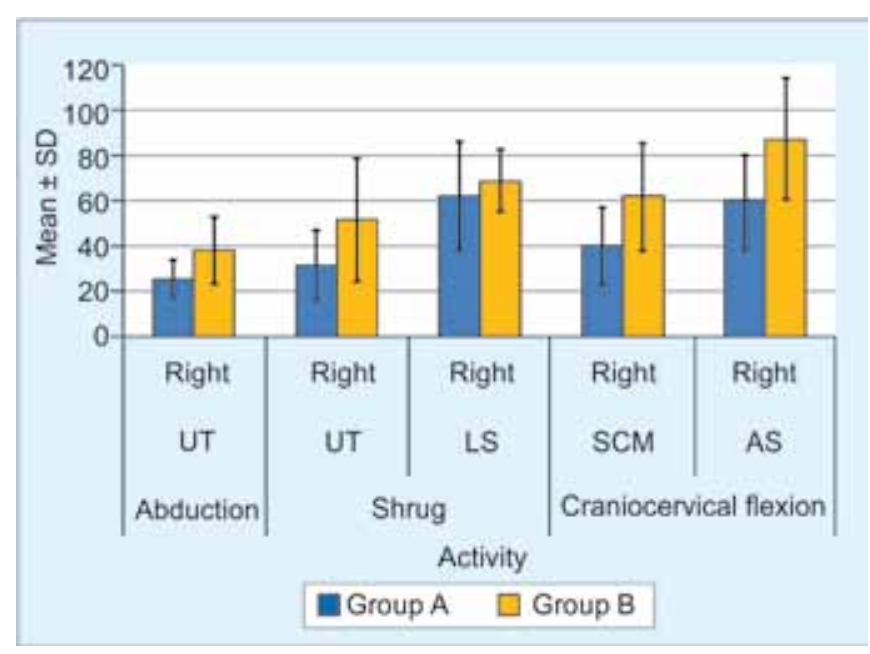

Graph 3: Comparison between groups A and B of right side activity

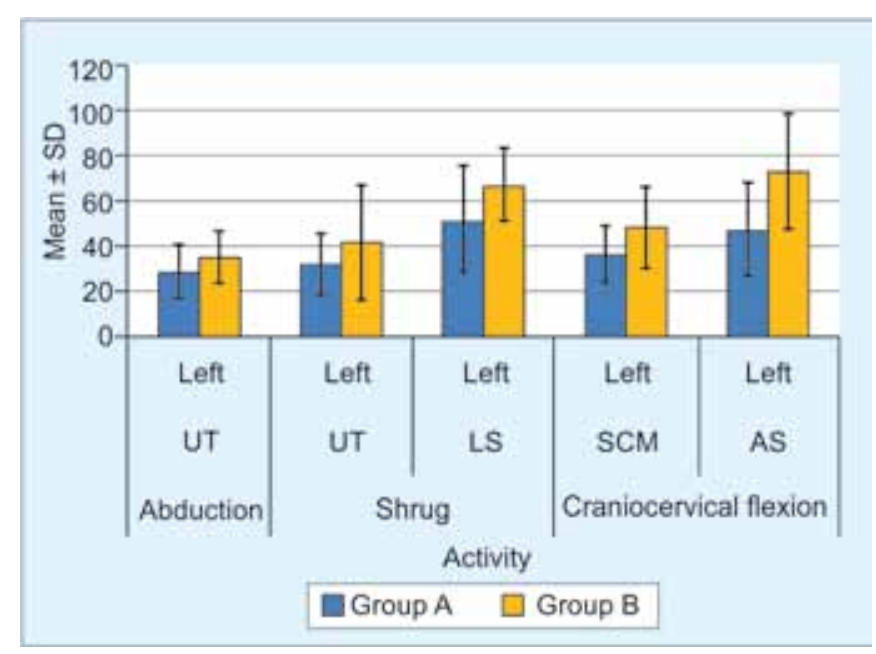

Graph 4: Comparison between groups A and B of left side activity 
model best explains the increased EMG activity observed in the patients. ${ }^{12}$

Knost B et al suggested that internal psychological tension or exposure to stress caused increased muscle tension and this led to lower pain perception and overtime became a pain inducing mechanism, thus, leading to vicious pain-tension cycle. ${ }^{16}$

Only specific muscles demonstrated statistically significant differences during the performance of particular tasks, e.g. right-sided UT demonstrated greater activity as compared to control group during performance of abduction and left-sided LS during performance of shrug. Significant difference was observed in activation pattern of both right and left-sided SCM and AS during performance of craniocervical flexion. Similar findings were observed by Falla D et al in their study on patients with chronic neck pain where they concluded that people withneck pain demonstrateanaltered pattern of muscle activation characterized by reduced deep cervical flexor muscle activity during a low load cognitive task and increased activity of superficial cervical flexor muscles during both cognitive tasks and functional activities. $^{7}$

A forward head posture has been associated with cervical pain syndromes and linked to muscle dysfunction. As explained by Janda, this forward head posture is associated with increased tension of LS and UT muscles. Since, the upper fixator attaches to the cervical spine and if they are over activity along with forward drawn shoulders that is protracted and elevated shoulder. Then, there is compensatory hyperlordosis of the cervicocranial junction. This tends to result in SCM becoming overactive. $^{17}$

Further, over activity of LS was observed in the patient group as compared to the control group. Rosenthal $\mathrm{R}$ observed similar finding in his study where he stated that forward head posture is associated with changes in proximal musculoskeletal structures comprising cervical erector spinae, UT, LS and anterior vertebral neck flexors and associated joints. Muscle and soft-tissue imbalances may affect the alignment and biomechanics of upper quadrant structures causing hyperextension of upper cervical spine, flattening of lower cervical spine, elevation and forward protraction of shoulders. These muscle imbalances lead to over activity of LS along with other muscles. ${ }^{18}$

This increased superficial cervical flexor muscle activity can also be attributed to forward head posture. Yip $\mathrm{CH}$ et al have reported that patients with neck pain have small craniovertebral angle and thus greater forward head posture and greater neck disability. ${ }^{19}$

Increased UT muscle activity was seen during the performance of abduction to $90^{\circ}$ and hold which can be explained on the basis of learned guarding response as described by Roe $\mathrm{C}$ et al in their study on patients with whiplash associated disorder grade 2 on performance of the dynamic task. He described this persistence of increased EMG level as compared to active side due to the decreased ability to relax their trapezius muscles probably as a result of learned guarding response. ${ }^{20}$

Thus, these findings are considered to be responsible for the increased EMG activity in muscles of patients with chronic neck pain of nontraumatic origin in this study. Thus, above discussion diverts the physical therapist toward working for the goal of decreasing the increased muscle tension in patients with chronic neck pain of nontraumatic origin.

\section{CONCLUSION}

It can be concluded from the present study that neck muscles in patients with chronic neck pain showed a significant increased level of EMG activity in neck muscles during performance of static tasks as compared to asymptomatic controls.

\section{REFERENCES}

1. Lucas KR, Polus BI, Rich PS. Latent myofacial trigger points: their effect on muscle activation and movement efficiency. J Bodywork Movement Ther 2004;8(3):160-166.

2. Rieger-Kreigh, Keysor JJ. Skeletal malalignments of the lower quarter: correlated and compensatory motions and postures. JOSPT 1996;23(2):164.

3. Kasman GS, Cram JR, Wolf SL. Clinical applications in surface electromyography: chronic musculoskeletal pain. Gaithersburg, Md: Aspen Publishers; 1998.

4. Bansevicius D, Sjaastad O 'Cervicogenic headache: the influence of mental load on pain level and EMG of shoulder-neck and facial muscles. Headache 1996;36(6):372-378.

5. Nederhand MJ, Ijzerman MJ, Hermens HJ, Baten CTM, Zilvold G. Cervical muscle dysfunction in the chronic whiplash associated disorder grade 2. Spine 2000;25(15):1938-1943.

6. Nederhand MJ, Hermens H, Ijzerman MJ, Turk DC, Zilvold G. Cervical muscle dysfunction in the chronic whiplash associated disorder grade 2 : the relevance of the trauma. Spine 2002;27(10):1056-1061.

7. Falla D, Jull G, Hodges PW. Feedforward activity of the cervical flexor muscles during voluntary arm movements is delayed in chronic neck pain. Exp Brain Res 2004;157(1): 43-48.

8. McLean L. The effect of postural correction on muscle activation amplitudes recorded from the cervicobrachial region. J Electromyogr Kinesiol 2005;15(6):527-535.

9. Mork PJ, Rofl H. Westgaard. Long-term electromyographic activity in upper trapezius and low back muscles of women with moderate physical activity. J Applied Physiol 2005;99(2): 570-578.

10. Daniels, Lucille. Muscle testing; technique of manual examination. 3rd ed. London WB Saunders Company; 1972.

11. Bansal A, et al. Altered activation pattern in patients with chronic neck pain. Ind Medica 2008;2(1):208-213. 
12. Elert J, Kendall SA, Larsson B, Marsson B, Gerdle B. Chronic pain and difficulty in relaxing postural muscles in patients with fibromyalgia and chronic whiplash associated disorders. J Rheumatol 2001;28(6):1361-1368.

13. Travell JG, Rinzler S, Herman M. Pain and disability of the shoulder andarm. J Am Med Assoc (Chicago) 1942;120(6): 417-422.

14. Schmidt RF, Kniffki K-D, Schomburg ED. Der Einfluss kleinkalibri-gerla, H Struppler, (editors), Therapie der Spastik. Verlag für an-Muskelafferenzen auf dem Muskeltonus. In H Bauer, WP Koel-gewandteWissenschaft, München: 1981. p. 71-84.

15. Johansson H, Sojka P. Pathophysiological mechanism involved in genesis and spread of muscular tension in occupational muscle pain and in chronic musculoskeletal pain syndromes: a hypothesis. Medical Hypothesis 1991;35: 196-203.

16. Knost B, Flor H, Birbaumer N, Schugens MM. Learned maintenance of pain: muscle tension reduces central nervous system processing of painful stimulation in chronic and subchronic pain patients. Psychophysiology 1999;36(6): 755-764.

17. Janda V. Muscles and motor control in cervicogenic disorders, assessment and management. In: Grant R, editor. Physical Therapy of the cervical and thoracic spine. New York, Churchill Livingstone. 2nd ed. 1994. p. 261-285.

18. Rosenthal $\mathrm{R}$. The predictive value of gross motor development, posture and upper quadrant stability for TMD in children and young adults: a preliminary study. The Internet J Allied Health Sci Practice 2005;3(1):1-10.

19. Yip $\mathrm{CH}$, Chiu TT, Poon AT. The relationship between head posture and severity and disability of patients with neck pain. Man Ther 2008 May;13(2):148-152.

20. Roe C, Brox JI, Saugen E, Vollestad NK. Muscle activation in the contralateral passive shoulder during isometric shoulder abduction in patients with unilateral shoulder pain. J Electromyogr Kinesiol 2000;10(2):69-77. 